\title{
A quantitative microbial risk assessment of helminth ova in reusing sludge for agricultural production in developing countries
}

\author{
I. Navarro ${ }^{1}$, B. Jiménez ${ }^{1}$, E. Cifuentes ${ }^{2} \&$ S. Lucario ${ }^{1}$ \\ ${ }^{I}$ Department of Environmental Engineering, Institute of Engineering, \\ Universidad Nacional Autónoma de México, México \\ ${ }^{2}$ National Institute of Public Health, México
}

\begin{abstract}
Helminth ovum (HO) is the main biological concern when reusing sludge for agricultural production. Worldwide sludge norms consider a maximum allowable value for this pathogen of $0.25-1 \mathrm{HO} / \mathrm{gTS}$. Such a threshold may be unaffordable to most developing countries, due to: (a) a very high original content of a wide variety of helminth ovum in sludge, and (b) the lack of technology to inactivate up to 2-3 log. This paper presents the actual risk caused by the use in agricultural land of treated sludge at the US-EPA and WHO limits, as well as the achievable content in sludge treated with affordable technology in developing countries, by using a quantitative microbial risk assessment (QMRA). This research developed a dose response curve for the Ascaris lumbricoides infection (Beta-Poisson model), to estimate the risk due to the ingestion of carrots grown in biosolids-amended soil and eaten raw. Using@Risk, risk estimates were constructed. The results indicated that the daily risk of infection was between 9.0 $\mathrm{x} 10-5$ and $5.0 \times 10-2$. The QMRA proved to be a useful tool to determine that the risk not only is not considerably higher but also can be managed in different ways, other than only by sludge treatment. The pollution of crops by helminths could be controlled by using different sludge application rates, limiting the kind of crops to be grown and introducing efficient produce washing methods.
\end{abstract}

Keywords: agriculture, biosolids, dose response curve, helminth ova, quantitative microbial risk assessment, sludge. 


\section{Introduction}

Helminth ova (HO) are considered the main biological health risk when applying biosolids on agricultural soils [1]. Helminth ova are commonly detected in sludge in developing countries in greater concentrations $(70-735 \mathrm{HO} / \mathrm{gTS})$ than in developed ones ( $<1-13 \mathrm{HO} / \mathrm{gTS}$ [2]). Additionally, an increasing number of developing countries are setting up regulations to treat and reuse biosolids based on the limits established for helminth ova by the U.S. EPA [3] or WHO [1], namely 0.25 and $1 \mathrm{HO} / \mathrm{gTS}$, respectively. Even in those places where the sludge recommended treatment methods are affordable, results show HO inactivation efficiencies of 70-95\% [2] involving final contents of 4-37 HO/gTS in treated sludge from developing countries. In other words, the above-mentioned limits are not fulfilled.

U.S. EPA limits and WHO guidelines for helminth ova were established based on limited epidemiological evidence and by the performance of different sludge treatment methods, and not by estimating the actual health risk. From a literature survey, it seems that human dose-response relationships for Ascaris or Taenia (types of helminth) have not been developed yet [4].

Quantitative microbial risk assessment (QMRA) is emerging as a useful tool for developing standards for human exposure to pathogens [5]. The best probabilistic estimates have been obtained using epidemiologic data from actual outbreak studies conducted mostly in developed countries [6, 7] for Salmonella, Giardia and Cryptosporidium. When applying QMRA, the first step is to define the best distribution model fitting observed infection rates as a function of pathogen exposure doses. The most commonly used models are the exponential and the Beta-Poisson, although others can also be used.

Considering QMRA has not been applied to assess helminth risks through exposure to polluted water, sludge or soil, and the lack of dose-infection curve, the aim of this research is to make a contribution to fill this gap. Thus, the objective of this research was to build up a risk-based model for Ascaris lumbricoides (A. lumbricoides) infection designed for untreated wastewater exposure (i.e., land crop irrigation), and apply it to assess human risks associated with A. lumbricoides exposure from crops grown in biosolid-enriched soil.

\section{Methodology}

\subsection{Dose-response assessment}

The dose-response model was developed using epidemiological data on $A$. lumbricoides infection rates from the Mezquital Valley, Mexico [8, 9, 10] and the water quality data of the wastewater used for crop irrigation in the valley. The scenario considered was the consumption of uncooked vegetables irrigated with untreated wastewater. For the development of the dose-response relationship, the fitness of data for the exponential (eqn. 1) and Beta-Poisson (eqn. 2) models was analyzed considering the following equations [11]: 


$$
\begin{gathered}
P(d)=1-\exp (-r d) \\
P(d)=1-\left(1+\left(\frac{d}{N_{50}}\right)\left(2^{1 / \alpha}-1\right)\right)^{-\alpha}
\end{gathered}
$$

In these equations $\mathrm{P}(\mathrm{d})$ is the risk of infection in an individual due to the ingestion of an average number of organisms in a dose; $d$ is the total number of organisms in a known consumed amount of vegetables; $\mathrm{N}_{50}$ is the median infective dose, and $\mathbf{r}, \alpha$ and $\beta$ are model parameters. To define the best-fit doseresponse relationship for $A$. lumbricoides infection, the chi-squared goodness of fit test was applied.

The epidemiological data developed by Cifuentes et al [8] consists of rates of A. lumbricoides infection determined through stool parasitological tests from the following population groups: children under the age of 5, children between 5 and 15 years old, and older than 15, from different communities in the Mezquital Valley. He found that the groups at higher risk were children under 15 for all sites, with a high annual $A$. lumbricoides prevalence rate of $10-17 \%$ exposed to untreated wastewater used for irrigation. Therefore, children under 15 years old were selected as representing the target population in developing the dose response model (table 1).

Table 1: Data, $\quad$ a,b of prevalence of $A$. lumbricoides infection (Mezquital

\begin{tabular}{|c|c|c|c|c|}
\hline \multirow[t]{2}{*}{ Age group } & \multirow[t]{2}{*}{ Sites } & \multirow{2}{*}{$\begin{array}{c}\text { Population } \\
\text { sample } \\
\text { size }\left(\mathrm{n}_{\mathrm{i}}\right)\end{array}$} & \multicolumn{2}{|c|}{ Ascaris prevalence } \\
\hline & & & $\begin{array}{r}\text { Popu } \\
\text { (p }\end{array}$ & $\begin{array}{l}\text { fected } \\
(\%)\end{array}$ \\
\hline \multirow[t]{3}{*}{$0-4 y$} & Raw wastewater ${ }^{(2)}$ & 341 & 34 & 10.0 \\
\hline & Rojo Gomez reservoir & 335 & 46 & 13.7 \\
\hline & Raw wastewater ${ }^{(1)}$ & 396 & 59 & 14.9 \\
\hline \multirow[t]{3}{*}{$5-14 y$} & Raw wastewater ${ }^{(2)}$ & 759 & 94 & 12.4 \\
\hline & Raw wastewater ${ }^{(1)}$ & 817 & 132 & 16.2 \\
\hline & Rojo Gomez reservoir & 698 & 115 & 16.5 \\
\hline
\end{tabular}
Valley).

a) Cifuentes et al [8]; b) Blumenthal et al [10]; c) Cifuentes et al [9])

(1) Rainy season prevalence infection

(2) Dry season prevalence infection

The population groups selected by Cifuentes et al [8] correspond to different communities due to the change in helminth ova content in wastewater as it flows through the valley as a consequence of sedimentation in reservoirs (table 1).

Data on the A. lumbricoides content and viability in wastewater developed by Jimenez et al [12] was used to estimate the content in crops. The $A$. lumbricoides content and viability was measured using a U.S. EPA [13] analytical method for quantification and incubation. In total, 24 values of Ascaris content $(\mathrm{k})$ were used and varied between 33 and 73 A. lumbricoides/5L with 52-93\% viability. 
To estimate the content of $A$. lumbricoides in crops, it was assumed that $10 \mathrm{~mL}$ of wastewater remains in $100 \mathrm{~g}$ of produce [14]. This assumption implied that the Ascaris content in crops varied from 0.42 to 1.15 Ascaris per $100 \mathrm{~mL}$ of water in the crop.

Population from the Mezquital Valley consumes some crops cultivated using untreated wastewater of varying degrees of quality. Because of lack of data on type of crops and the amount of produce consumed, a consumption of $100 \mathrm{~g}$ of raw crops per week per child during one year was assumed.

\subsection{Quantitative risk estimate}

Results from an experimental study performed to measure the total amount of helminth ova content and the $A$. lumbricoides percentage in carrots grown in soil fertilized with biosolids were used for the QMRA. A detailed description of the data was published elsewhere [15]. Results from that research as well as the best infection model for $A$. lumbricoides developed with the data described in the dose-response assessment were used to estimate the probability of infection from eating raw carrots, with the following assumptions:

- Exposure group of concern: children under 15 years old.

- Use of four different initial helminth ova contents in biosolids (HO/gTS) (table 2): the international standards of $0.25 \mathrm{HO} / \mathrm{gTS}$ [3] and $1 \mathrm{HO} / \mathrm{gTS}$ [1], and the minimum and maximum concentration values expected in affordable sludge treatment in developing countries, 4 and $37 \mathrm{HO} / \mathrm{gTS}$ respectively.

- Application to agricultural land of four different helminth ova rates $\left(\mathrm{HO} / \mathrm{cm}^{2}\right)$, corresponding to vegetable nutrient requirements in the region of study (table 2).

- A. lumbricoides content measured as $90 \%$ of the total helminth ova $(\mathrm{HO} / \mathrm{g})$ content in carrots $\left(\mathrm{C}_{\text {carrot }}\right)$ (table 2$)$.

Table 2: Helminth ova content in biosolids, on land-application rates and $A$. lumbricoides content in carrots (data from Jimenez et al [15]).

\begin{tabular}{l|c|c|c|}
\hline \multirow{2}{*}{$\begin{array}{l}\text { Biosolids } \\
\text { (HO/gTS })\end{array}$} & \multirow{2}{*}{$\begin{array}{c}\text { Land } \\
\text { Application } \\
\left(\mathrm{HO} / \mathrm{cm}^{2}\right)\end{array}$} & \multicolumn{2}{|c|}{ Carrots } \\
\cline { 3 - 4 } & $(\mathrm{HO} / \mathrm{g})$ & $\begin{array}{c}\mathrm{C}_{\text {carrot }} \\
(\text { Ascaris } / \mathrm{g})\end{array}$ \\
\hline 0.25 & 0.003 & 0.004 & 0.003 \\
\hline 1 & 0.011 & 0.015 & 0.013 \\
\hline 4 & 0.042 & 0.059 & 0.053 \\
\hline 37 & 0.390 & 0.546 & 0.491 \\
\hline
\end{tabular}
$\mathrm{C}_{\text {carrot }}$ is the $A 0$. lumbricoides content in carrots after harvesting

- The carrot consumption (IR carrot) variability was addressed assuming a mean intake range estimate of 28-38 g per event for children under 15 years in the USA [16], as well as the mean, $90^{\text {th }}$ and $99^{\text {th }}$ percentile of carrot intake distribution [17] (table 3).

- Child consumption of raw crops once a week.

- A 1 [1] and a $2 \log$ A. lumbricoides reduction due to crop washing. 
Table 3: $\quad$ Ingestion rates for carrot.

\begin{tabular}{|l|c|}
\hline & $\mathrm{IR}_{\text {carrot }}(\mathrm{g})$ \\
\hline Minimum $_{(1)}$ & 28 \\
\hline Maximum $_{(1)}$ & 38 \\
\hline Mean $_{(2)}$ & 43 \\
\hline $90^{\text {th }}{ }_{(2)}$ & 100 \\
\hline $99^{\text {th }}{ }_{(2)}$ & 183 \\
\hline
\end{tabular}

(1) Mean range of produce quantities consumed by children [16]

(2) Consumption data per eating event in three days [17]

$\mathrm{IR}_{\text {carrot }}=$ carrot consumption rates used for QMRA

\section{Results}

\subsection{Dose-response relationships for Ascaris lumbricoides}

The exponential (eqn. 1) and Beta-Poisson (eqn. 2) models were used for fitting the prediction of $A$. lumbricoides infectivity. The parameters of the models were calculated using the maximum likelihood method. The values of the parameters that minimize the deviance $\left(\mathrm{Y}_{\min }\right)$ are the maximum likelihood estimates. If the optimum value of the deviance $Y_{\min }$ is less than the tabulated chi-squared value $\chi^{2}$ at $\mathrm{k}-\mathrm{j}$ degrees of freedom ( $\mathrm{k}$ is the number of doses, 24 in this study, and $\mathrm{j}$ the number of parameters in the model-one for the exponential and two for the BetaPoisson), then the fit is considered acceptable [18]. Tables 4 and 5 show the parameters obtained for both dose-response models.

Table 4: Exponential model parameters for the crop ingestion exposure pathway.

\begin{tabular}{|l|c|c|c|c|}
\hline $\begin{array}{l}\text { Exposure Pathway } \\
\text { Ingestion }\end{array}$ & A. lumbricoides content & $\mathbf{r}$ & $\mathrm{Y}_{\min }$ & $\chi^{2}$ \\
\hline Crops & $\begin{array}{c}0.42-1.15 \\
\text { Ascaris } l . / 100 \mathrm{ml}\end{array}$ & 0.039 & 43.289 & 35.17 \\
\hline
\end{tabular}

r: model parameter; $Y_{\min }$ : Minimum deviance; $\chi^{2}:$ chi-square value at 23 degrees of freedom

Table 5: Beta-Poisson model parameters for the crop ingestion exposure pathway.

\begin{tabular}{|l|c|c|c|c|c|c|}
\hline $\begin{array}{l}\text { Exposure } \\
\text { Pathway } \\
\text { Ingestion }\end{array}$ & $\begin{array}{c}\text { A. lumbricoides } \\
\text { content }\end{array}$ & $\mathrm{N}_{50}$ & $\alpha$ & $\beta$ & $\mathrm{Y}_{\min }$ & $\chi^{2}$ \\
\hline Crops & $\begin{array}{c}0.42-1.15 \\
\text { Ascaris } l . / 100 \mathrm{ml}\end{array}$ & 859 & 0.104 & 1.096 & 5.074 & 33.924 \\
\hline
\end{tabular}

$\alpha, \beta$ : model parameters; $\mathrm{N}_{50}$ : median infectious dose; $\chi^{2}:$ chi-square value at 22 degrees of freedom.

From theses tables, it can be observed that the fit to the exponential doseresponse model fails a goodness of fit test to data $\left(\mathrm{Y}_{\min }>\chi^{2}\right)$ (table 4$)$, while the 
fit to the Beta-Poisson relationship is acceptable (table 5). In fact, the BetaPoisson model with $\beta=1.1$ and $\alpha=0.104$ parameters (table 5) was the best approximation found, and the infections were predicted with this model.

\subsection{Risk estimate}

The risk calculations associated with a single week of exposure to carrots eaten raw, estimated with the Beta-Poisson model developed are shown in tables 6 and 7. The risk assessment of consuming uncooked carrots grown on biosolidamended soil is in the range of $6 \times 10^{-2}$ to $9 \times 10^{-5}$ per week, considering 2 ova $\log$ reductions due to produce washing. This shows that infection risks depend also on the application rate and not only on the helminth ova content in sludge.

For the study region the model showed that if the U.S. EPA standard or the WHO criteria ( 0.25 and $1 \mathrm{HO} / \mathrm{gTS}$, respectively) were applied, the overall risk of infection could be greater than $10^{-4}$ and the $A$. lumbricoides infection rate for carrots eaten raw would be 0.009 to $0.23 \%$ (table 6 ), for the ingestion rates assumed, and if the washing procedure is enhanced to remove 2 ova log. These rates are considerably lower than those actually observed (10-17\%).

Table 6: $\quad$ Risk estimate based on U.S. EPA and WHO standards.

\begin{tabular}{|c|c|c|c|c|}
\hline \multirow{3}{*}{$\begin{array}{l}\text { Biosolids } \\
\text { (HO/gTS) }\end{array}$} & \multirow{3}{*}{$\begin{array}{c}\mathrm{IR}_{\text {carrot }} \\
\text { (g/d) }\end{array}$} & \multicolumn{3}{|c|}{ Carrots } \\
\hline & & \multirow{2}{*}{$\begin{array}{c}\text { Risk } \\
(2 \text { log) }\end{array}$} & \multicolumn{2}{|c|}{ Infection $(\%)$} \\
\hline & & & $2 \log$ & $1 \log$ \\
\hline 0.25 & 28 & $9.0 \mathrm{E}-05$ & 0.009 & 0.09 \\
\hline 0.25 & 43 & $1.4 \mathrm{E}-04$ & 0.014 & 0.14 \\
\hline 0.25 & 100 & $3.2 \mathrm{E}-04$ & 0.03 & 0.32 \\
\hline 0.25 & 183 & 5.9E-04 & 0.06 & 0.57 \\
\hline 1 & 28 & $3.5 \mathrm{E}-04$ & 0.04 & 0.35 \\
\hline 1 & 43 & $5.4 \mathrm{E}-04$ & 0.05 & 0.53 \\
\hline 1 & 100 & $1.3 \mathrm{E}-03$ & 0.13 & 1.19 \\
\hline 1 & 183 & $2.3 \mathrm{E}-03$ & 0.23 & 2.07 \\
\hline
\end{tabular}

The prediction of $A$. lumbricoides infection may be greater than $10^{-3}$ if the minimum (4 HO/gTS) and maximum $(37 \mathrm{HO} / \mathrm{gTS})$ content of $\mathrm{HO}$ expected in affordable sludge treatment in developing countries were used. The $A$. lumbricoides infection rate for carrots eaten raw varied from 0.14 to $6 \%$ (table 7 ), if the washing procedure is enhanced to remove 2 ova log, which is considered viable from unpublished results.

When the application of a sludge with $4 \mathrm{HO} / \mathrm{gTS}$ was considered (table 7), the model showed that the infection risk rate was $0.9 \%$ for carrots, for the maximum crop consumption rate. Produce washing also had an important effect on the infection risk rate. The carrot infection rate with $4 \mathrm{HO} / \mathrm{gTS}$ in sludge is $6 \%$ if washing is performed such that only 1 ova log is removed, but it can be reduced to $0.9 \%$ if the washing procedure is enhanced to remove 2 ova $\log$. 
Table 7: $\quad$ Risk estimate from once-a-week exposure to carrots eaten raw with biosolids $A$. lumbricoides content in developing countries.

\begin{tabular}{|c|c|c|c|c|}
\hline \multirow{3}{*}{$\begin{array}{l}\text { Biosolids } \\
\text { (HO/gTS) }\end{array}$} & \multirow{3}{*}{$\begin{array}{l}\mathrm{IR}_{\text {carrot }} \\
(\mathrm{g} / \mathrm{d})\end{array}$} & \multicolumn{3}{|c|}{ Carrots } \\
\hline & & \multirow{2}{*}{$\begin{array}{c}\text { Risk } \\
(2 \mathrm{log})\end{array}$} & \multicolumn{2}{|c|}{ Infection (\%) } \\
\hline & & & $2 \log$ & $1 \log$ \\
\hline 4 & 28 & $1.4 \mathrm{E}-03$ & 0.14 & 1.31 \\
\hline 4 & 43 & $2.1 \mathrm{E}-03$ & 0.21 & 1.94 \\
\hline 4 & 100 & $4.9 \mathrm{E}-03$ & 0.49 & 4.00 \\
\hline 4 & 183 & $8.7 \mathrm{E}-03$ & 0.87 & 6.36 \\
\hline 37 & 28 & $1.2 \mathrm{E}-02$ & 1.22 & 8.09 \\
\hline 37 & 43 & $1.8 \mathrm{E}-02$ & 1.81 & 10.55 \\
\hline 37 & 100 & $3.8 \mathrm{E}-02$ & 3.77 & 16.19 \\
\hline 37 & 183 & $6.0 \mathrm{E}-02$ & 6.02 & 20.59 \\
\hline
\end{tabular}

$\mathrm{IR}_{\text {carrot }}=$ carrot consumption rates used for QMRA

The infection risk observed with $37 \mathrm{HO} / \mathrm{gTS}$ in sludge is notably higher; it varied from an acceptable $1 \%$ up to $21 \%$ (table 7 ). As observed in previous cases, the health risk is highly dependent on the consumption rate and the efficiency of washing procedure. If the mean consumption rate is considered representative for carrot ingestion among children $(28-43 \mathrm{~g} / \mathrm{d})$, then the infection rates vary from 1 to $11 \%$, assuming 2 and 1 ova log reduction respectively. This result is within the range obtained for $4 \mathrm{HO} / \mathrm{gTS}$ content in sludge. Moreover, if the consumption rate of $100 \mathrm{~g} / \mathrm{d}$ for carrots is considered as a reasonable maximum exposure in a week for children the prediction for the $A$. lumbricoides infection rates $(4 \%)$ would be within the observed prevalence, if a reduction of 2 ova log is obtained by produce washing.

\section{Discussions}

\subsection{Confidence on the dose-response model for the Ascaris lumbricoides infection}

The U.S. EPA and WHO guidelines for helminth ova were not developed using a risk-based framework, nor were they intended to be. Therefore, a risk-assessment approach may provide numerical limits to achieve a defined threshold for human health protection, among other control measures.

In the absence of a dose-response relationship for $A$. lumbricoides in the literature, we decided to develop one with the best available data instead of using a relationship for another pathogen, as is frequently reported. That is, the doseresponse relationship developed predicts children (under 15 years old) $A$. lumbricoides infection rather than on illness from crops eating raw (irrigated with wastewater). The statistical procedure used is identical to that used to fit exponential and Beta-Poisson models by Haas et al [11].

Regarding the dose-response relationship obtained from available infection data [8], it was derived from $A$. lumbricoides prevalence using stools from a 
large sample of children, in a population in which Ascariasis is an endemic infection resulting in a certain degree of immunity. In the case of helminthiases in developing countries, there may be at least three species, A. lumbricoides, Trichuris trichiura, and Schistosoma with differences regarding infectivity and severity of illness that need to be considered and, ideally, a dose-response relationship for each particular species should be obtained.

Assuming the dose-response relationship derived from reported data [8] is representative for children younger than 15, living near agricultural sites irrigated with raw wastewater, we may be overestimating risk based on the assumption that all viable $A$. lumbricoides ova in both wastewater and crops are species which infect humans. In addition, consumption rate of $100 \mathrm{~g}$ of vegetable assumed may represent an overestimate of exposure. In fact, one of the main sources of uncertainty in the dose-response relationship proposed is the crop consumption rate. Appropriate data regarding types of crops, consumption intake and frequency is needed to reduce those uncertainties and increase the confidence on infection predictions.

\subsection{Confidence on QMRA for biosolids}

Assessing risk associated with the reuse of biosolids in agricultural production need to take into consideration that pathogen exposure may not be homogeneous. The results of this research indicated that this could be due to several factors: type of sludge treatment process used, nutrient requirements for enriching agricultural soil, rate of biosolid application, crop category and the harvestingconsumption time. Some of these factors, as well as produce washing and consumption patterns (amount and frequency, cooked or non-cooked produce) among the concerned population have all temporal dimensions, while others have spatial ones. To improve confidence on the distribution of risks obtained, those factors leading to increased variability need to be better characterized.

Variability in consumption behaviour is known to be relevant in QMRA used in wastewater irrigation scenarios [19]. The selection of vegetable consumption rates (table 3) allowed us to account for our lack of knowledge about this parameter estimate (uncertainty) in Mexico, and to include inherent natural variation (variability) in the risk assessment conducted. Thus, the infection risk could have been overestimated by using such conservative assumptions.

Finally, to improve overall QMRA conducted for biosolids reuse in agriculture, it is necessary to obtain ascariasis epidemiological information, which correlates attack rates of infectivity with measurements of $A$. lumbricoides content in vegetables eaten raw. There is no doubt that a sensitivity analysis needs to be achieved for the biosolids model in order to identify parameters contribution to infection variability and uncertainty prediction, mainly for those describing consumption rates.

\subsection{Helminth ova content in biosolids and control measures}

The results show that the risk from carrots eaten raw depends not only on the land application rate of biosolids with specific helminth ova content, but also on 
biosolids content. These two variables have a great influence on $A$. lumbricoides content in crop produce. Additionally, the QMRA showed that the risk of infection is highly dependent on consumption rates and on the efficiency of produce washing.

These results suggest that U.S. EPA and WHO available standards for biosolid application in agricultural production are too strict. For concentration range expected in affordable sludge treatment in developing countries (4 to 37 $\mathrm{HO} / \mathrm{gTS})$, the higher infection rates estimated (6\% and $21 \%$ respectively) for carrots might be reduced $(0.5 \%$ and $4 \%$ respectively) to the prevalence rates observed if the washing practice is enhanced to remove 2 ova log, and if the maximum consumption rate for carrots is less than or equal to $100 \mathrm{~g} / \mathrm{d}$.

Consequently, regulations targeting biosolid reuse in developing countries should address the challenge of deciding first acceptable infection risk and, second, putting in place an integral framework for risks management, involving additional health protection measures: (a) an affordable treatment process, (b) crop restriction policy, (c) different sludge application rates, and (d) efficient produce washing methods, among others.

\section{Conclusions}

The contribution made in this paper consisted of integrating epidemiological and environmental data to evaluate the risk using the QMRA approach. It shows that multidisciplinary work is needed to help decision makers define evidence-based strategies for effectively protecting human health under different circumstances. Our data indicated that it would be possible to use higher helminth ova content standards than those proposed by U.S. EPA and WHO in biosolids from developing countries without significantly increasing the risks. Our study also pointed out that health risk is not only associated with the helminth ova content in sludge, but also with a wide variety of factors such as biosolid application rates, category of crop, produce washing and crop consumption rates. These considerations may allow policymakers to define different cost-benefit and control strategies.

\section{References}

[1] WHO, Guidelines for the Safe Use of Wastewater, Excreta and Greywater. World Health Organization, Geneva, 2006.

[2] Jimenez, B. \& Wang, L., Sludge Treatment and Management in Municipal Wastewater Management. Developing Countries: Principles and Engineering, eds. Ujang, Z. \& Henze, M. International Water Association Publishing, London, U.K., 237-292, 2006.

[3] U.S. EPA, 40 Code of Federal Regulations. Part 503. Fed. Regist. 58(32), 9248-9415, 1993.

[4] NRC, Biosolids Applied To Land: Advancing Standards And Practices. Prepublication copy, National Research Council, National Academy Press, Washington, DC, pp 282, 2002. 
[5] Haas, C. N., Progress and data gaps in quantitative microbial risk assessment. Wat. Sci. Technol., 46(11-12), 277-284, 2002.

[6] Rose, J. B., Haas, C. N. \& Regli, S., Risk assessment and control of waterborne Giardiasis. Am. J. Public Health, 81(6), 709-713, 1991.

[7] Teunis, P. F. M., Nagelkerke, N. J. D. \& Haas, C. N., Dose response models for infectious gastroenteritis. Risk Analysis, 19(6), 1251-1260, 1999.

[8] Cifuentes, E., Blumenthal, U., Ruiz-Palacios, G. \& Bennett, S., Health impact evaluation of wastewater use in Mexico. Public Health Review, 92(19), 243-250, 1991.

[9] Cifuentes, E., Blumenthal, U., Ruiz-Palacios, G., Bennett, S., Quigley, M. \& Romero-Alvarez, H., Problemas de salud asociados al riego agrícola con agua residual en México. Salud Pública de México, 35(6), 614-619, 1993.

[10] Blumenthal, U.J, Duncan, M., Ayres, R.M., Cifuentes, E., Peasey, A., Stott, R., Lee, D.L. \& Ruiz-Palacios, G., Evaluation of the WHO nematode egg guidelines for restricted and unrestricted irrigation. Wat. Sci. Technol., 33(10-11), 277-283, 1996.

[11] Haas, C. N., Rose, J. B. \& Gerba, C. P., Quantitative Microbial Risk Assessment. John Wiley \& Sons, Inc. New York, USA, 1999.

[12] Jimenez, B., Chavez, A. \& Maya, C., Characterization of the water and wastewater used to irrigate the Mezquital Valley. Internal Report No. 2345, Engineering Institute, UNAM, Mexico, Unpublished manuscript, 1992.

[13] U.S. EPA, Environmental Regulations and Technology, Control of Pathogens and Vector Attraction in Sewage Sludge. EPA/625/R92/013, Washington D.C, 1992.

[14] Shuval, H., Lampert, Y. \& Fattal, B., Development of a risk assessment approach for evaluating wastewater reuse standards for agriculture. Wat. Sci. Technol., 35(11-12), 15-20, 1997.

[15] Jimenez, B., Austin, A., Cloete, E. \& Phasha, C., Using Ecosan sludge for crop production. Wat. Sci. Technol., 5(54), 169-177, 2006.

[16] U.S. EPA, Child-Specific Factors Handbook. National Centre for Environmental Assessment. EPA/600/P-00/002B, Washington D.C, 2002.

[17] U.S. EPA, Exposure Factors Handbook, Vol II Food Ingestion Factors. Washington D.C, 1997.

[18] Haas, C. N., Thayyar-Madabusi, A., Rose, J. B. \& Gerba, C. P., Development of a dose-response relationship for Escherichia coli O157:H7. Int. J. Food Microbiol., 56, 153-159, 2000.

[19] Hamilton, A. J., Stagniti, F. S., Premier, R. \& Boland, A. M., Is the risk of illness through consuming vegetables irrigated with reclaimed wastewater different for different population groups? Wat. Sci. Technol., 54(11-12), 379-386, 2006. 